\title{
Do Improve Typing Skill But No Significant Difference between Drill-Based and Game-Based Typing Software
}

\author{
Chun-Hung Lin ${ }^{1}$ and Eric Zhi-Feng Liu ${ }^{2}$ \\ ${ }^{1}$ Graduate Institute of Information and Learning Technology \\ National University of Tainan \\ No. 33, Sec. 2, Shu-Lin St., Tainan \\ Taiwan \\ ${ }^{2}$ Graduate Institute of Learning and Instruction \\ National Central University \\ No. 300, Jhongda Rd., Jhongli City, Taoyuan County 32001 \\ Taiwan \\ sjohn1202@gmail.com, totem@cc.ncu.edu.tw
}

\begin{abstract}
Extended Summary. Improving typing skill can help students use computers to deal with different kinds of tasks more efficiently. In the past, typing software was commonly used to train students' typing skill, and they usually didn't have much attractive multimedia effect. In recent years, games have become more and more popular, and one of the reasons is that games have lots of attractive elements, like lots of multimedia effect and interesting scripts. About the educational effect of typing games, game is more interesting than traditional instruction, and that's the reason why people use typing games to train their typing skill. This study tried to realize the effect on typing skill of drill-based and game-based typing software, and proposed possible design direction for typing software.

There were 160 second year junior high school students participating in this study. The students studied in a junior high school in middle Taiwan, and they came from five different classes. After excluding six invalid samples, 82 students were males $(53.2 \%)$ and 72 students were females $(46.8 \%)$. Pretestposttest control group design was used in this study. The independent variable was different types of typing software. There were 92 students in the control group, and they used drill-based typing software to learn typing. There were 62 students in the experimental group, and they used game-based typing software to learn typing. The dependent variable was typing speed. The difference of typing speed between pre-test and post-test and the effect on typing speed of different software would be compared.

The result showed that both kinds of typing software could improve students' typing speed, but the effect on typing speed between the two kinds of software didn't reach significant difference. The result indicated that both entertainment and learning design direction were beneficial for learning typing skill, but different kinds of design also showed different disadvantages and limitations. Therefore, it is better to consider the two aspects at the same time when design edutainment software, and try to keep the balance between the two elements to produce the optimal learning effect. The future studies may confirm if the learning effect from both learning element and entertainment element is better than the learning effect only from learning element or entertainment element.
\end{abstract}

Keywords: Computer-assisted instruction, Typing speed, Drill-based typing software, Game-based typing software. 